\title{
HYPOTHESIS PROCESSING AS A NEW TOOL TO AID MANAGERS OF MENTAL HEALTH AGENCIES IN SERVING LONG-TERM REGIONAL INTERESTS
}

\author{
MANFred Kochen \\ Mental Health Research Institute, University of Michigan, \\ Ann Arbor, Michigan 48104 (USA) \\ (Received: 16 June, 1975)
}

SUMMARY

Mental health planning is partly a political process, involving the articulation of the long-range interests of a regional community, formation of consensus among key people and the appropriate investment of authority, power and responsibility. Conflicts between the short-term self-interests of planners and the longer-term general interest usually arise. This paper claims that it is feasible to increase the expected number of cases in which a region's longer-term interest is served without radical changes in existing planning processes or ideologies.

The means for doing this are new kinds of information systems that serve planners as tools to increase their awareness about assumptions, hypotheses and problem representations. The conceptual and technological bases for developing such systems stem from progress in artificial intelligence in the direction of hypothesis-processing algorithms. The proposed application to mental health planning is described. Arguments are presented to show how the use of such tools would increase the likelihood that longer-term regional interests are served.

\section{SOMMAIRE}

La planification de la santé mentale est en grande partie une tâche politique. Elle implique la coordination des intérêts d'une collectivité locale, du consensus de personnalités importantes et d'investissements appropriés. Habituellement, des confits apparaissent entre l'intérêt propre à court terme, des planificateurs et l'intérêt général à plus long terme. Cet article montre qu'il est possible de favoriser les intérêts à long terme d'une région, sans avoir d̀ en modifier radicalement la planification. 
Pour y arriver, on peut utiliser de nouveaux systèmes d'information, qui permettent aux planificateurs de mieux percevoir les hypothèses et la représentation des problèmes.

Les bases conceptuelles et technologiques qui permettent de développer de tels systèmes, vont des progrès en intelligence artificielle aux algorithmes testant des hypothèses.

L'application à la planification de la santé mentale est décrite. Des arguments sont présentés qui montrent comment l'utilisateur de tels outils pourrait servir les intérêts à long terme d'une région.

\section{INTRODUCTION}

In this paper we propose a new tool to aid managers of mental health care agencies in the formulation of policies to serve a region's long-term interest. The tool takes the form of a collection of medical information systems to which a new feature is added: the processing and use of hypotheses to stimulate question asking, to improve management and to foster attitudes of sharing. This new feature and these ideas are applications to this important area of health planning of work in artificial intelligence during the past decade (Kochen, 1974a). (Although artificial intelligence has stimulated significant advances in computer science and technology (e.g. higherlevel languages like LISP, new conceptualisations of problem solving, pattern recognition), its aims and methods have recently been questioned (Sir James $\mathrm{L}$. Lighthill, F.R.S., Part I: Artificial intelligence: A general survey, Cambridge University, July, 1972). The selection of a problem of practical interest (in contrast to chess and logic) to be used as a research vehicle-to stimulate a specific fundamental problem amenable to elucidation via AI-may be the best strategy to counter the valid objections.)

The use of information systems for planning mental health facilities, services and manpower is a special case of health planning in general (MacKay, 1957; Alderson, 1972). Organisational problems are common to both. The primary importance of these was already recognised (Anon., Cogwheel Report, 1967) in 1967. In 1970 there was a proposal for the creation of a 'community physician' title at the regional health board level in the UK (Alderson, 1972, p. 28). Mental health planning presents planners with problems that do not occur as acutely in other health planning situations: how to deal with numerous unstated assumptions about the goals and methods of mental health care, how to cope with a diversity of values that are more political in mental health, how to help mental health professionals clarify their own belief systems, cope with potential conflicts, become more accountable to the needs of a region. It has recently been shown (D. R. Atkinson, Community influence on the generation of program evaluation data in mental health services, unpublished Ph.D. dissertation, University of Michigan, 1975) that human service agencies try 
to limit external control over their own evaluation data which may be potentially embarrassing. This further confounds the problems of mental health planning. To deal with such problems, we introduce the idea of updatable files that record explicit statements of beliefs held by planners and others for use by individuals and groups to enhance problem clarification.

Political-organisational factors in policy formulation, such as those which arise in problems when data needed for planning are owned by independent agencies, are relatively new to some members of the medical profession who are thrust into managerial positions in mental health institutions-positions for which they have not been trained and for which they may not be inclined. Computerised medical information systems have failed to live up to the expectations of their users more often than not. Very capable managers, on the other hand, have used information systems to great advantage, despite organisational and other obstacles. Increased familiarity in the use of information systems, under good organisational conditions, can improve the performance of both categories of managers.

The effect of introducing computers into organisations has been studied since 1960 (Postley, 1963) and the organisational factors have repeatedly been said to be primary determinants of acceptance and success. In reaction to the early piecemeal approaches to medical information systems, the total systems approach came into fashion (Lawton, 1970; Dessau, 1969), but has not proved itself to be very costeffective, either.

The most promising approach appearing on the information systems landscape is the 'evolutionary system' development by increments, with each increment serving a useful purpose in its own right (Barnett and Sukenik, 1969). While the system is not produced in its totality all at once, it is conceptualised completely and built up in stages. Both the conceptualisation and incremental design decisions are the result of continuing negotiations with users and the community. The hypothesisprocessing procedure described here as a new feature in medical information systems is an instance of such an increment. Its essential details, too, are subject to constant review and require consensual acceptance of its key users. The timing at which increments are developed is determined by the coincidence of what can be done with available technology and organisation and what someone with resources and needs is willing to have built, installed and used.

The understanding of tools to help in mental health systems planning and policy formulation to serve regional interest is impeded by three obstacles of nearly equal importance: problems of a conceptual nature of clarifying basic issues and goals; problems of management and organisation; and technical problems.

To show that the proposed new hypothesis-processing tool can help managers of mental health agencies to better serve the long-term interests of their region, we first sketch the nature of the tool and show how it might be used to fit into the planning process; then we present arguments to show that it will improve management, sharing, policy formulation and better serve the regional interest. 
Imagine a community with population $P$ and two managers, $M_{1}$ and $M_{2}$, of mental health agencies, both assigned to serve $P$. They either report to, or obtain their funding from, a third agency headed by $J$, which is even more directly responsible to $P$ than are $M_{1}$ and $M_{2}$.

Call the proposed tools $I S_{1}, I S_{2}, I S_{J}$ and $I S_{P}$. These are information systems owned and used by $M_{1}, M_{2}, J$ and the general public, respectively. $I S_{1}$ consists of: (1) three data bases, $D B_{1 H}, D B_{1 D}$ and $D B_{1 T}$; (2) procedures for updating, maintaining and using these data bases; and (3) organisational arrangements and protocols governing the distribution of control, costs and benefits in the utilisation of these information systems. Some of these data bases and procedures are computerised when that is cost-effective. Which technology to use (files could also be kept in graphic or audioform) is not as critical as whether planners will record their assumptions explicitly and then use these files as a mirror to raise their consciousness about them.

The first and most important data base, $D B_{1 H}$-and this is also the novel feature introduced in this paper-consists of hypotheses. Each of these is a statement, together with a weight indicating how strongly $M_{1}$ believes it. It has the form: 'If $I\left(M_{1}\right)$ find myself in a situation - - and if I take actions - - , then I expect the change - - - in my situation, which I evaluate according to my personal preferences and priorities as follows:-...'

A highly simplified example of such an hypothesis is: 'If I provide psychotherapy services for clients suffering from depression, I expect that 10 per cent will return to life in the community, job, home, without impairment, which I value highest among the possible outcomes.' The cost, duration, availability of this service could have been included. Expectations about other outcomes might have been mentioned. Comparison with alternative services (e.g. use of drugs) could have been explicated. To the extent that $M_{1}$ is aware of, and willing to record, even privately, his personal motives, the statement may mention that certain outcomes are likely to lead to increases in his agency's power, budget, his salary and goodwill from the community, which he values in that order. Such a statement then begins to resemble the hypotheses tested by sampling or surveys in other health or social science areas. A planner or practitioner who holds such a belief may not completely reject it (or accept an alternative) even when a statistical test would compel scientists to make the inference because the probability of erroneous acceptance or rejection is very low. That may be due to the planner's doubts about whether tie most important attributes and values of the situation are captured by alternative hypotheses, about the priorities assigned to such attributes and values. In any case, the program we propose for helping him to update the file of $D B_{1 H}$ of the beliefs he holds at one time is to induce him to make his problem representation, his values, quite explicit. 
It should be obvious to anyone examining $D B_{1 H}$, whose interests are being served by $M_{1}$, and that alone is a valuable feature of hypothesis-processing.

The second data base, $D B_{1 D}$, consists of data used in forming and supporting such hypotheses. It might contain case records or statistics about depressives treated by psychotherapy with various outcomes. It is also used to answer specific questions. It is from the statistics in $D B_{1 D}$, together with the subjective probability judgements and degrees of importance that $M_{1}$ attaches to various outcomes, that the weights associated with the hypotheses are computed. For the most part, the data are supplied by $M_{1}$ himself or by his staff, or are transferred from public data sources.

The third data base, $D B_{1 T}$, consists of a topical directory to the concepts and their (assigned) logical relations to one another. The notion of a 'growing thesaurus', one which adapts constantly to both the patterns of use and its inputs so as to become increasingly responsive to the users' needs, is quite applicable here (Kochen, $1974 b$; Reisner, 1965). $D B_{1 T}$ is used by $M_{1}$ to answer general questions, enabling $M_{1}$ to converse in a language that evolves as both he and the tool adjust and become more effectively coupled with one another. It performs some of the functions now attributed to 'computer-aided instruction'.

The following procedures govern the activity of these data bases:

(a) Eliciting from $M_{1}$ agreement and effort to collect, compile and enter data about his personal attitudes and performance in providing mental health services.

(b) Searching the store of hypotheses, $D B_{1 H}$, in response to a request from $M_{1}$, for those most relevant-i.e. of highest weight according to $M_{1}$ 's values in the light of his present situation. This procedure has been described as an algorithm and implemented as a general computer program (Hantler and Kochen, 1974).

(c) Displaying to $M_{1}$ hypotheses considered relevant in a form that he can easily register and readily integrate into his image (Boulding, 1967).

The data base also contains hypotheses intended to stimulate $M_{1}$ 's awareness of his own hypotheses when presented with the display, which tries to elicit from $M_{1}$ alternative actions to replace the ones in the display, and to clarify the assumptions under which he is operating.

(d) Eliciting from $M_{1}$ what action he did, in fact, take when he was in a condition and state in which he used this tool, as well as the consequences for $M_{1}$ which actually ensued.

(e) Modifying of the weights of all the stored hypotheses on the basis of the up-to-date $D B_{1 D}$. An algorithm for steps (b) and (e) has also been implemented as a computer program (Hantler and Kochen, 1974). It also uses a reweighting procedure that makes the set of weights converge on one 'correct' hypothesis when exactly one exists that accurately represents the world.

(f) Updating $D B_{1 H}$ by revisions of existing hypotheses or by adding new ones to co-exist with, or replace, old ones and which have a greater chance of being useful or relevant improves this kind of learning. 
(g) Automatic transcription of hypotheses with highest weight into $I S_{P}$ if $M_{1}$ concurs, or possibly as the outcome of a legal procedure if he does not.

Some of the organisational arrangements governing the information system $I S_{1}$ are critical. In the first place, $M_{1}$ personally owns $I S_{1}$. He alone can decide what is entered into its data base and stored there; who can access it, how and when. It is important to distinguish between $I S_{1}$ and another possible information system associated with the office, role or slot that at present happens to be occupied by $M_{1}$. The latter is owned by the organisation, possibly by $J$ if $J$ paid for it. Although $I S_{1}$ is personalised for $M_{1}$, it may justifiably be paid for by public funds if this will shift $M_{1}$ 's performance to better serve the public interest. Public funding need not preclude private ownership by $M_{1}$. It is not out of the question, for example, that US presidential papers and tapes are a particular President's private property if their being so is most in the country's long-term interest.

Secondly, $M_{1}$ can use his information system to communicate with his peer $M_{2}$, his boss or sponsor, $J$, and his community, $P$, about selected items.

$M_{1}$ is able to edit his data bases for the purpose of making available to $M_{2}, J$ and $P$ edited versions of his $I S_{1}$. Similarly, he can copy selected portions of edited data bases that $M_{2}, J$ or $P$ are willing to make available to him (e.g. 'expletive deleted' in presidential tape transcripts).

The key feature of $I S_{P}$ is that it is freely accessible to everyone. Data, hypotheses and tutorials will be displayed to any member of $P$. The public can enter data as well as hypotheses; both are kept together with validity indicators. The only-and serious-limitation is the problem of limited capacities for a given cost, which leads to waiting lines and overloads. The population as a whole would not enter data; only its most articulate spokesmen, ombudsmen or those reporting survey data would. It can be maintained only with the informed consent of specific individuals affected.

Consider, for example, the situation of two persons responsible for running a psychiatric clinic. One believes in the efficacy of psychotherapy for manic depressives. The other, $M_{2}$, favours treatment by chemotherapy or behaviour modification techniques. The first enters hypotheses that express these beliefs in his $D B_{1 H}$. These statements may be composed by him, stimulated by his experience, by texts he considers authoritative, by contrary opinions expressed by $M_{2}$, etc. The data he collects in $D B_{1 D}$ will reflect these beliefs. Thus, he may monitor the number of psychotherapeutic man-hours per case from opening to closing it. He may then plan to provide for enough such man-hours to meet projected demand without congestion. Since he takes the efficacy of psychotherapy for granted, he may use his topical directory, $D B_{1 T}$, only to help him associate with the concept of 'congestion' other concepts such as 'variance of number of people waiting' that help him plan more reliably.

$M_{2}$ may collect data in $D B_{2 D}$ that are based on and support belief statements in $D B_{2 H}$ about the 'production function' of newer methods of psychiatric management. 
If he is a confirmed believer in one of these in the way that $M_{1}$ is a devotee of psychotherapy, then $M_{2}$ 's use of $I S_{2}$ resembles $M_{1}$ 's use of $I S_{1}$. Both $M_{1}$ and $M_{2}$ would, however, be better served if $D B_{1 T}$ and $D B_{2 T}$ would remind or stimulate its user to reflect, to inquire into, the adequacy and effectiveness of their favoured form of service. At the very least, $D B_{i H}(i=1,2)$ would remind $M_{i}$ of his own assumptions at the right time, making him continually aware of them in explicit form; $D B_{i T}$ would help him form further hypotheses and create and implement more imaginative plans based on a more analytical, a more inquiry-oriented mode of thought; $D B_{i D}$ would help $M_{i}$ base these plans on a firmer foundation of relevant facts.

How is the store of hypotheses built up and maintained? The public store can be built up from published information sources, and treated as are editorial pages of a newspaper or their equivalent on public TV. A private store can be created if its owner or his well-trained and trusted aide were to attend a seminar where he learns how to analytically represent hypotheses. He sets up the topical directory, as well as the necessary data base, to serve him personally in the research for monitoring evidence for these hypotheses.

To be sure, many managers may not be inclined to use such complex tools. If it takes more initial effort to learn or maintain skills in the use of a tool than it seems worth, then its use will decline. Initially, stress should be placed on those aspects of the proposed tool that are simple, in the use of which managers can become fluent with little effort and which are obviously attractive to them. It must blend with the managers' concerns and styles. Not all managers want to reveal their values, even to themselves. Blurring may serve a useful purpose. Perhaps the most attractive feature of the proposed tool from this point of view is that it has a growing, adaptive, evolutionary feature that facilitates increasing personalisation and negotiation with the user community.

\section{THE UTILITY OF HYPOTHESIS-FORMATION AIDS FOR IMPROVED MANAGEMENT AND IMPROVED CO-OPERATION AND CO-ORDINATION}

In this section we offer arguments to show that the tools proposed above increase the likelihood that the long-term interests of the region's population, $P$, will be served. We start with the premise that in any organisation there may be conflicts between the long-term interests of the general public and the short-term interests of individual managers, which are the primary forces in the planning process. The public, too, may be split into classes with long-term conflicts of interest (Hollingshead and Redlich, 1958) and this would require several public information systems. To confine the subject, we will not consider that realistic possibility. In what follows, premises on which the arguments are based are marked (A) following such a statement if it is an assumption that the reader is asked to accept, $(\mathrm{H})$ if it is a testable hypothesis and (C) if it is a conclusion based on prior arguments or inferences. 


\section{Basis of argument}

Three conditions about the dynamics of planning are necessary and sufficient for the general, long-term interest of $P$ to be served. (A)(H)

(a) Long-term interests or goals of $P$ are articulated by one of the managers, $M_{j}$, whose statement about the general regional interest is $S$. $S$ may not at first be completely known or free of internal contradictions. (A)

(b) There is consensus among all those involved in shaping and administering the policies concerning $S$. The consensus may at first be very low and of limited scope, but increases with time above a critical threshold. (C)

(c) $M_{j}$ or someone equally committed to $S$ must be assigned appropriate measures of power, responsibility and authority needed to get all the involved managers to perform the tasks to serve $S$ even if these tasks are against their shortterm interests. $(\mathrm{C})(\mathrm{H})$

To test this hypothesis is to select as the dependent variable a measure of the extent to which the general longer-term regional interest is served. This variable is estimated for two regions that differ in an essential way only in the three independent variables: (1) a 'legislative' who articulates the common interest; (2) presence or absence of consensus among key people; and (3) a sufficiently powerful, responsible 'executive' with appropriate authority.

How to operationalise these independent variables - the third is actually three in itself-is far from clear and raises several important conceptual issues. Subjective interests, which relate to the distribution of attention and expectations, need to be distinguished from objective interests. These may be specified by the probability of reinforcing experiences and of their motivational consonance. Communal interests may be articulated by an ombudsman or a $P$ spokesperson, rather than a manager. There may be higher values, such as mercy and compassion, that by implicit general agreement, transcend divergent community interests and priorities.

We next try to show that use of an appropriate hypothesis-processing information system will increase the probability that each of the three conditions-interest articulation, interest consensus and executive authorisation-will be met.

\section{Emergence of general interest articulator}

Consider first the emergence of $M_{j}$, an articulator of the common interest. The public system, $I S_{P}$, is likely to accumulate data indicative of needs for mental health services to $P(A)$. If, for example, there is an unusual increase in the number of 'crazies' reported by police among those in jail or if the homicide or suicide rates increase sharply, and if allowance has been made for changing standards of definition and reporting (Bauer, 1966), this may indicate the need for expanded or better services, perhaps even social reforms. Responsible or powerful mental health officials may assert that the long-term interest of the community is to keep all those considered to be abnormal under 24-hour surveillance. This is translated into a testable hypothesis to the effect that: Most of the members in the community prefer 
to have the less-well-adjusted members of their community (which might some day include themselves or members of their families) perpetually isolated and rendered inoffensive to others or themselves, to a more costly attempt at cure and rehabilitation. This can be analysed into several hypotheses, one about effectiveness, one about beliefs, etc. To test any of these, information system $I S_{P}$ calls for the collection and use of relevant data. Alternatively, $I S_{j}$ may form hypotheses about the general interest that would be verified by data already in its data bases.

Such hypotheses are broadcast to managers, who may enter them into their IS's. In a somewhat similar way, each manager, $M_{i}$, forms his hypotheses (reflecting his self-interests) which he enters into his $I S_{i}, I S_{i}$ then points out to him any hypotheses that represent a coincidence of interest.

A good public hypotheses base, $I S_{P}$, will make a manager who uses it aware of how his interest can be made to coincide with that of the community $(H)$. The probability of an $M_{j}$ announcing himself as articulator of community needs and the statement $S$ emanating from him is likely to be greater with an $I S_{P}$ than would be the case without one (C). Of course, information alone would not enhance interest articulation if the timing were wrong, for example.

\section{Enhancement of consensus formation}

To gain some insight into the role of information systems in consensus formation, suppose that two managers, $M_{1}$ and $M_{2}$, are competing for the $M_{j}$ position for which $M_{1}$ or $M_{2}$ will be chosen by $J$. An hypothesis regarding the actions of $M_{1}$ (and $M_{2}$ ) is that each will: (a) persuade $J$ that he is better qualified for the job than his competitor and well enough qualified to meet the requirements; (b) ensure that news of his ability to satisfy community needs reaches $J$ (but news of his failures reaches $J$ only with good explanations, if at all); (c) use selected (as described earlier) parts of his $I S_{1}$ to assess himself relative to his competitor's qualifications, what he thinks $J$ will expect, or the requirements of the job; (d) help him improve his performance during the period in which $J$ is observing him; and (e) assess the strength of his competition.

Consensus formation requires shifts of priorities and images and possibly some trading in powers, authorities and responsibilities (A). As each participant in consensus formation moves in small steps from old positions to new ones, he wants to be sure that his losses are minimal (assuming still that self-interest is the primary motivating force) and that he manoeuvres into the best possible position $(\mathrm{H})$. In this he will use his $I S$ as an intelligence aid (A). Beyond this, however, consensus formation requires that each $M_{i}$ be persuaded, by his superiors, peer pressures and by community pressure, that $M_{i}$ must serve long-range general interests rather than short-term self-interest.

What would persuade $M_{1}$ or $M_{2}$ to accept a statement of the common interest in place of one that reflects his self-interest? Such statements would have to enter $M_{1}$ 's (or $M_{2}$ 's) data base from sources he considers reliable and of which he 
approves. He must be assured that they do not represent interests inimical to his. If possible, such statements should reflect common ground between his own and the community's intercsts. It is the task of $M_{j}$ to stimulate $M_{1}$ (and $M_{2}$ ) to form or solicit such hypotheses for entry into their data bases.

In no case should the user of an information system feel that he has contributed to help anyone to destroy the integrity of his personality, his freedom to adhere to certain fundamental values. Trust in others is maintained better if each user has control over his own information system and over data about him in the public information system. This implies a decentralised collection of individuals' information systems, interconnected through the public system (C). Since the system described in the previous section is to have these properties, its use is likely to enhance consensus (C).

\section{Investment of authority}

In some organisations not everyone is clear about $S$, nor about his own responsibilities, authority and power; nor is he clear about the behavioural criteria by which his performance can be judged objectively with regard to his responsibilities. Here the $I S$ is said to serve the manager as would a counsellor, a consultant or a trained staff assistant. It does not compute recommendations for him but it articulates what $M$ already feels to be the case, it points out possible contradictions and inconsistencies, and it contrasts viable alternatives for action. It confronts $M$ with how his condition may appear from diverse perspectives, possibly to his peers and to $J$. As it may increase his awareness of how his actions might conflict with his own interests and values, so it might make him aware of possible conflicts between his own and others' values and interest. Moreover, it provides an attractive tool (from his perspective) that can be used by the community he is serving to render him more accountable.

\section{Information sharing}

Good information systems require some degree of information sharing for cooperative tasks such as prevention. For other tasks, such as medical management of the afflicted, open competition among the service agencies may lead to the best possible service. We now argue that, under certain conditions, the kind of $I S$ discussed so far are likely to increase the extent of information sharing. We argue that $I S_{1}$ helps to persuade $M_{1}$ that the benefit-cost ratio of sharing exceeds that of not sharing. This is equivalent to sajing that $I S_{j}$ helps convince $M_{1}$ that if and when he offers to share data with his adversary, $\boldsymbol{M}_{2}$, then $\boldsymbol{M}_{2}$ will reciprocate in kind and in good faith. This process is analogous to negotiations in a prisoner's dilemma situation (Rapoport and Chammah, 1965).

$M_{1}$ will be convinced sufficiently to make a move toward sharing by evidence that $M_{2}$ has begun to take such a step (A). It is likely to be helpful if that evidence arrives within a time interval that is so short that the same evidence can be 
transmitted to $M_{2}$ and $M_{1}$, so that it appears to each as if they are taking their steps simultaneously (H). The kind of $I S$ 's described in the previous section have this capability (A). This would tend to increase the probability of sharing (C). It is, of course, desirable that mental health practitioners reveal their biases and continually keep in touch with the realities of the community they are serving. The exposure of the strongest hypotheses to public scrutiny should go at least part way towards achieving this. Public interest in the hypotheses by which those concerned with their mental health are operating should provide pressure for revelation of such information.

\section{Objections to the argument}

It is preferable to replace 'interest to be served' by 'needs to be met'. Even though most of the region's population agrees about its interests, it may remain unaware of its needs. A small, but articulate, minority, perhaps the opinion leaders, may shape the community's values and state what the majority accepts as its interests on issues about which it is not very knowledgeable, conscious or sensitive. Thus, we may see aberrations in which mental health planning, as any other kind of planning, is seen through ideological blinders rather than in a spirit of free inquiry. The best safeguard against infiltration of one or another ideological bias may be to ensure open access for everyone to the public information system. All the managers should have equally good information systems for their own use. There should also be an effective system of communication among them that helps their biases to cancel one another.

There is the real possibility that the data bases of both the bureaucrats and the public will be of low quality. It may be in the short-term interests of all concerned to keep them uniformly low. Perhaps a mechanism that enhances self-improvement built into the $D B_{i T}$ of all data bases, and drawing upon the best scientific understanding as it becomes available, may counter that objection. Current ideas towards communal learning mechanisms (Kochen, 1975) may pave the way.

It is possible that more informed participants in a group process may inhibit, rather than enhance, consensus formation, because there is more opportunity for diverse individual interpretations of data, for diverse representations of problems, for greater awareness of individual values and interests. Only informed people who are aware of their own and one another's biases can agree to disagree on certain issues. They may decide to select areas of common agreement and trade these against areas on which to disagree. Such processes may, on balance, favour consensus formation.

Educating people with strong views, clarifying issues and problems more completely, may hinder conflict resolution. The role of information, knowledge and cognitive understanding alone is limited. Knowledge can be anxiety producing. Some people need predigested options, while others need a display of options with pros and cons, the use of consultants, aids to reaching agreement on attitudes and 
values to be shared. In all this, what understanding, knowledge, information to use when-what we have elsewhere called wisdom-is critical. Wise and competent managers and spokespersons can make use of the tools proposed here, although there is also the potential for misuse.

\section{CONCLUSION}

Planning mental health facilities affects the vital interests of many people in a region, including clients, servers, constituents (A). Many of these people are also involved in the planning process $(H)$. Conflicts of interests are the rule rather than the exception $(\mathrm{H})$. This makes planning primarily a political process. (The terms 'planning' and 'policy formation' are often used interchangeably or at least in conjunction. Harris (1965), House and Tyndall (1973) and others have identified several stages in this process: (1) problem identification; (2) development of policy alternatives; (3) comparative analysis of the alternatives' impact; (4) adoption of an alternative; (5) implementation. Although this is widely regarded as a linear time sequence which becomes a political process only after stage (3), we believe that many of the stages are concurrent, are returned to, and constitute a political process from, stage (1), with non-political, scientific inputs all along.) Group processes such as consensus formation and conflict resolution play a dominant role (A). This is also true for other kinds of social planning (A).

An important goal of regional planning is to identify and serve, when and where possible, the region's general long-term interest (A). Planners who have to identify and plan towards those interests are driven primarily by șhorter-term self-interest, and the two do not always coincide (A). Yet, it may now be possible to increase the expected number of cases in which a region's longer-term interest is served without any radical changes in existing planning processes $(\mathrm{C})$.

What helps to make this possible are new kinds of information systems. These serve planners as tools to increase awareness about their own assumptions, hypotheses and problem representations on which their planning is based. These tools are used to inject information into the political-planning process to intervene in it, to modify it towards enhanced consensus formation and identification of the general interest. Data thus injected stimulate the generation of shared-problem representations, modified images, new concepts and attitudes of sharing among key participants in the planning process.

The conceptual-and, to some extent, the technological-basis to develop and apply such new kinds of information systems derive from progress in intelligence in the direction of hypothesis processing. The decreasing cost and ready availability of powerful minicomputers and intelligent terminals connected to a large computing system or network make the technological aspects feasible. These are, however, overshadowed by organisational and economic obstacles. The increasingly 
widespread recognition of these central problems has led to several projects, including one in which the author is participating (see Acknowledgements), that are providing investigators with the needed experience and insight.

Therefore, further development of the kinds of information systems sketched here, plus experiments to evaluate their use in actual mental health planning situations, seem feasible and worth while. Yet the cost of even the most modest experiments in health information systems should not be underestimated. The volume of use must be quite large--possibly around $10^{4}$ transactions per month-for any kind of cost-effectiveness, and this means large data bases and high initial cost. The importance of skilful management, full-time long-term commitment by a competent staff in the organisations that will use the systems and which are to provide continuing support cannot be stressed enough. Nor must expectations about what the systems will do be raised above the hope their users are actually likely to express and translate into behaviour that determines the systems' success or failure.

We cannot claim that individual organisations who use such aids in the planning process will always produce results that serve the general regional interest better than would that same organisation without such aids. It is only more likely. Among several such organisations the expected number who succeed in this sense should increase. Moreover, for that to happen, enough organisations serving the same region will have to adopt the tool as well as a way to interact.

In sum, it seems likely that further progress in artificial intelligence and systems theory will be in conjunction with applications in biomedicine. The planning of mental health care systems is an important and challenging vehicle because its problems are still so ill-defined. Yet the infusion of ideas and techniques, such as described here, do offer some promise for progress.

\section{ACKNOWLEDGEMENTS}

Stimulating discussions with Dr. G. Quarton have been most valuable, as has been the challenge of relating it to problems arising from a study of decentralisation (NSF Grant GN-43385) and of barriers to the use of computerised records for mental health systems planners (DHEW Grant NY-1R01MB00160). Comments by K. W. Deutsch, F. Wallace and S. Brumer have also been very helpful.

\section{REFERENCES}

Alderson, M. R., Medical information systems. In (J. Rose (Ed.)): Computers in medicine, (Proceedings of the Second International Symposium held at Blackburn College of Technology and Design on 16 and 17 March, 1971). Dorchester, Dorset: John Wright \& Sons Ltd., 1972, pp. 24-33.

ANON., Cogwheel Report, A First Report of the Joint Working Party on the Organisation of Medical Work in Hospitals. London, H.M.S.O., 1967. 
BarnetT, G. O. and SukeniK, H. J., Hospital information systems II. In (J. F. Dickson, III and J. H. U. Brown (Eds.)): Future goals of engineering in biology and medicine (Proceedings of an International Conference, held at Washington, D.C., September, 1967). New York, Academic Press, 1969, pp. 268-83.

BAUER, R. W. (Ed.), Social indicators, Cambridge, Mass., MIT Press, 1966.

Boulding, K., The image, Ann Arbor, Michigan, University of Michigan Press, 1967.

Dessau, E., Hospital information systems I. In (J. F. Dickson, III and J. H. U. Brown (Eds.)): Future goals of engineering in biology and medicine (Proceedings of an International Conference, held at Washington, D.C., September 1967). New York, Academic Press, 1969, pp. 251-67.

HANTLER, S. and Kochen, M., ASP: A Program using stored hypotheses to select actions, J. of Cyber., 3 (1974) pp. 1-12.

HarRIS, B., Tools for Planning, J. Am. Inst. Planners, 31 (1965).

HollingsheAd, A. B. and ReDLICH, F. C., Social class and mental illness, New York, Wiley, 1958.

House, P. and TYNDALL, G. R., Models on policy making: A Guide to models. In: Government planning and operations, Princeton, Mathematica, Inc., 1973.

Kochen, M., Representations and algorithms for cognitive learning, Artif. Intell, 5 1974(a), pp. 199-216.

Kochen, M., Principles of information retrieval, Los Angeles, Melville/Wiley, 1974(b).

Kochen, M. (Ed.), Information for action: From knowledge to wisdom, New York, Academic Press, 1975.

LAwTON, M. D., Systems design for a management orientated hospital information system. In (M.E. Abrams (Ed.)): Medical computing-Progress and problems. London: Chatto \& Windus, 1970 , pp. 358-9.

MACKAY, D., Hospital morbidity statistics, GRO Studies on Medical and Population Subjects No. 4. London, HMSO, 1957.

Postley, J. A., Computers and people, New York, McGraw-Hill, 1963.

RAPOPORT, A., and С HAmmah, A. M., Prisoner's dilemma: A study in conflict and cooperation, Ann Arbor, University of Michigan Press, 1965.

REISNER, P., Semantic diversity and a 'Growing' man-machine thesaurus. In (M. Kochen (Ed.)): Some problems in information science, New York, Scarecrow Press, 1965, pp. 117-30. 